\title{
“HOT-BLOODED” ESTONIANS. ON ESTONIANS' FOLK CATEGORY OF EMOTIONS
}

\section{Ene Vainik}

Latvians have a teasing phrase for Estonians - 'hot-blooded', which ironically refers to the emotional dullness and inadequate - either apparent or actual - calmness of Estonians.

This article ${ }^{1}$ does not aim to compare the ethnopsychology of Estonians and Latvians, nor to measure the psychological characteristics inherent to the nation of Estonians (Tulviste 1998). It does strive to take a look at the folk psychology of Estonians - what is the attitude of Estonians to emotions and how the so-called average Estonian deals with emotions. By the end of this article it should also become clear why Latvians refer to us as they do.

The term folk psychology is used here to denote the understanding of psychic phenomena on the part of common people. Not the understanding of a single person, but that of the so-called average person. Admittedly, folk psychology is connected with the culture in which it has developed and the language people have taken into use for analysing such phenomena. Similarly to other unsophisticated treatments, the terms of folk psychology are not clearly definable or in direct correspondence with the words which are used at random and in parallel. Thus, Estonian folk psychology does not make a substantial difference between the meanings of the words emotsioon 'emotion' and tunne 'feeling'. These two words are used parallel, like numerous other pairs consisting of a foreign and a native word, where the use of the foreign word is more prestigious. For example, the Estonian equivalent of 'positive emotion' sounds more elegant than the simple 'good feeling'.

In modern Estonian folk psychology the word emotsionaalne 'emotional' tends to be used as an evaluative adjective. For instance, the sentence Ta on nii emotsionaalne, temaga ei saa rääkida 'She is so emotional, there's no point in talking to her' is likely to mean that the person in question is too emotional (which is bad) or Ärgem 
laskugem emotsioonidesse! 'Let's not descend to emotions!' (emotions are something to descend to and it would be better not to do it, otherwise võivad [---] emotsioonid üle pea kokku lü̈̈a 'emotions could close in above your head'). If there was an "emotional conversation" between the boss and the employee, it rather meant calling names than expressing warm feelings. It seems that if the positive or negative mark of an emotion has not been pointed out explicitly, the default connotation and evaluation is negative.

So it must be admitted that in Estonian folk psychology the category of emotion is vague rather than delimited, in addition it seems to carry an evaluative mark. While neither the nation, culture nor language is invariable in time, there are changes in the concepts and beliefs of folk psychology, too. To get a better overview of what the categories of emotion of Estonians is like at the beginning of the 21st century, I decided to conduct an empirical study of emotion vocabulary (Vainik 2001).

\section{STARTING POINTS}

The ideological basis for this approach originates from the linguistic relativity hypothesis (Whorf 1956): one's native language with its concepts influences and shapes the way how the world is seen and interpreted. This hypothesis leads to at least two substantial conclusions - one at the individual and the other at the collective level. For an individual it is important that linguistic competence significantly determines how he/she manages socially and emotionally. On the level of the society the conclusion is that through language research information about the culture and the people who carry it can be obtained. A major role is played by concepts which have formed in the culture and crystallised in the language, and by means of which information is conveyed.

In the collective consciousness the language-supported concepts in a specific field form a body of universal knowledge about this field, which is common to the majority of speakers of this language. For example the vocabulary that in a language is used to denote emotions and differentiate the nuances and intensity or duration levels plays a significant role in how emotions are popularly treated by the speakers of this language. ${ }^{2}$ 
Each person's relation to vocabulary and to concepts that it mediates is different. Some words are easily remembered and elicited they are in active use. Others are in passive use - one knows that such words and concepts exist, but it is more difficult to use them. Our daily life and how we succeed is more dependent on the words and concepts that are in active use, always at hand. The choice of emotion words that are in active use and easily available for a certain group of people, e.g. speakers of the Estonian language, shows which concepts are important for and frequently used by the specific group at a specific time. Consequently, by studying the available emotion vocabulary of Estonians we can get an idea which emotions are important for Estonians, which is their level of cognizance and how organised is a common person's view of the so-called internal world, i.e. what does an average Estonian's map of emotion landscape look like.

\section{ABOUT THE RESEARCH}

It is said that the concepts of a field of study, actually all concepts, and the words that represent them are not chaotically located in a person's head- on the contrary, they are located in quite a systematic way which facilitates classification (Viberg 1994: 170-171). If this statement is true, it should be easy for people - for instance in the tasks of free listing - to "leaf through their systematic catalogues" and present words by categories. On the basis of this presumption an empirical study was conducted using the so-called field method: ${ }^{3}$ in the course of oral interviews one hundred people of different sex, age and educational background were asked to make attempts of free listing emotions. ${ }^{4}$ The linguistic material collected as a result of the interviews was sequenced according to frequency and the position of naming; the form and meaning of recurring phrases was analysed (Vainik 2001).

The number of phrases collected in the course of these interviews was nearly five thousand and they were not directly emotion terms only. As the people were not to feel restricted during the experiments - they were encouraged to mention anything they could remember in connection with emotions in random order (similarly to the free associations method used in psychoanalysis) - a large part of the total corpus of this vocabulary is made up of people's indi- 
vidual associations with emotions (for example 'cosmos', 'cow', 'violet' etc). The recurring part of the vocabulary ( $3+n$ times), however, revealed the cognitive domains on which the category of emotions borders in the consciousness of Estonians, how the area of emotions is structured, which concepts belong to the basic level and which are the prototypical emotions of Estonians. But it also showed which emotions are not willingly acknowledged by Estonians or even prevented from entering the collective consciousness.

\section{POSITION OF FOLK CATEGORY OF EMOTION IN ESTONIANS' COLLECTIVE CONSCIOUSNESS}

The semantic space of a language, which could also be called the collective consciousness of the users of this language, is said to consist of cognitive domains that concentrate knowledge, experiences and meanings by subjects (Langacker 1987). Such cognitive domain or at least an independent natural category is also made up of emotion-related cognitive knowledge and experiences, which have crystallised in the language as emotion lexis.

On the basis of the results of this empirical study it is possible to outline which are the principal and prototypical representatives of the Estonians' field of emotions and which are peripheral, staying in the zone where the field of emotions borders on and intersects other cognitive domains. Naturally, it is not presumed that the fields are separated from each other by inflexible borders.

According to the semantic grouping of the words and concepts that emerged repeatedly $(3+n$ times) it can be concluded that in the collective consciousness of Estonians the emotion category is located in the intersection of three cognitive domains - the subjective physical space, the social space and the intrapsychic space. Figure 1 schematises these three main cognitive domains and the letter $\mathrm{E}$ marks the position of emotions in their intersection.

Each natural category has its centre and periphery. The most frequently and first mentioned words in the tasks of free listing are the basic terms of this category (Sutrop 2000), i.e. the basic terms of emotions in the Estonian language. These words are in correspondence with the basic-level objects of the Estonian folk emotion 


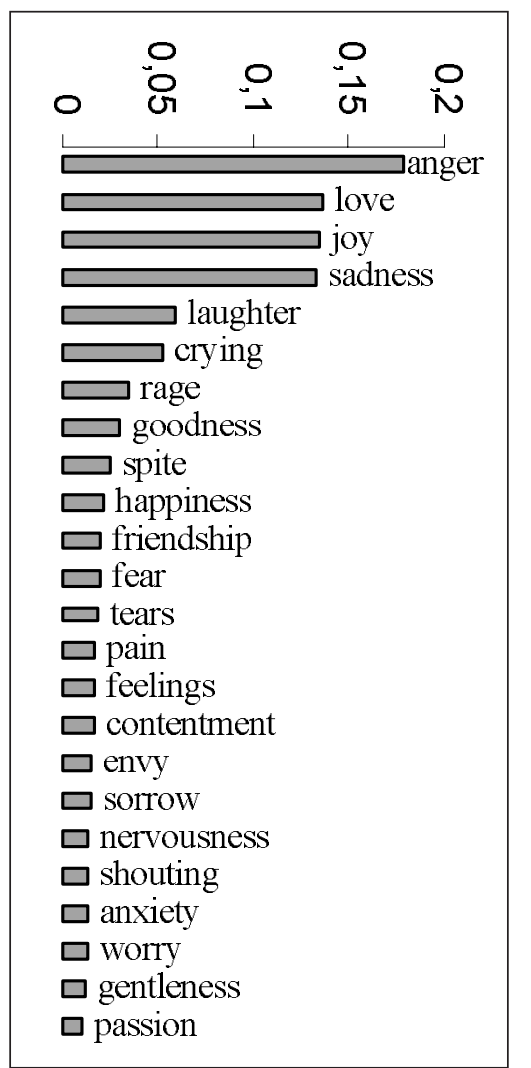

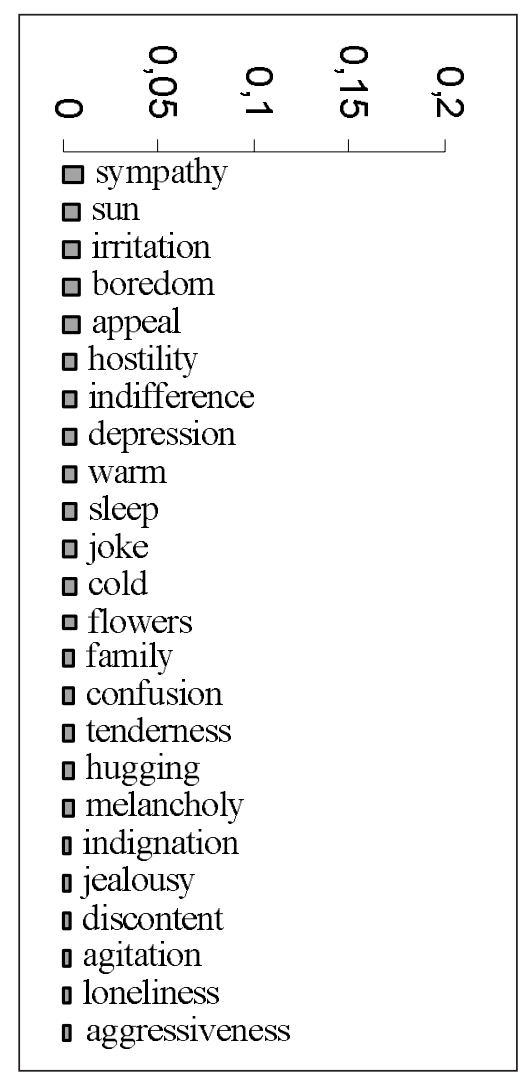

Diagram 1. Cognitive salience indices in the task of free listing of emotion terms. The total salience of the first four members of the folk category of emotion makes up 44 per cent of the total salience of all the words that emerged in the task of free listing, which means that the objects on the basic level of this category cover 44 per cent of the collective emotional consciousness of Estonians.

The remaining 56 per cent of the collective emotional consciousness was divided among 54 words. Such division expressly shows that in Estonians' common knowledge of emotions there is a compact core of the basic level, but off the basic level the folk category of emotion is diffusive. For a more detailed analysis of the cognitve salience of emotion terms and concept in the Estonian language see Vainik 2002.

Cognitive salience indices were calculated according to the formula (Sutrop 2001: 299-300): $S=F /(N \mathrm{mP})$, in which $S$ is the cognitive salience index, $F$ frequency of the word in the list, $N$ - total number of interviewees, $m P$ - the average position of the word (calculated according to the following formula: $m P=(S R j) / F$, in which $R j$ is the position of the word in an individual list). 


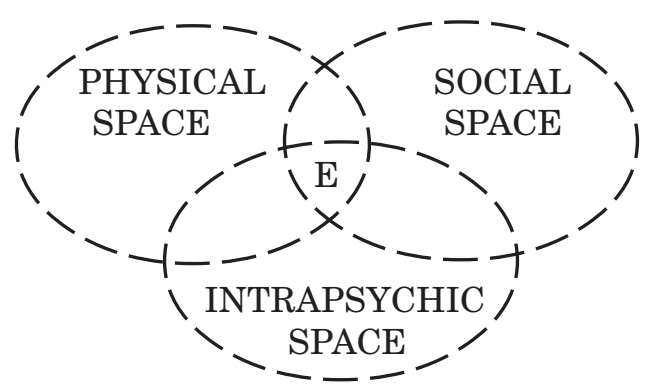

Figure 1. Position of emotion category in the collective consciousness of Estonians.

category - the basic level emotion concepts as the most prototypical representatives of the category (Kövecses 2000).

In the centre of the emotion category Estonians have the words viha 'anger', armastus 'love', rõom 'joy' and kurbus 'sadness', the cognitive salience of which appeared to be the highest. The index of cognitive salience shows the relation of the frequency and the average position of the word in the tasks of free listing. If the index of cognitive salience approximates one, it means that almost every informant elicited this word among the first; if the index is close to zero, it means that this word occurred to few people and even in that case, not among the first. Differences in the value of the cognitive salience index of members of the same category show how central and representative the concepts are from the aspect of the general meaning of the category. The difference between the basic terms and the non-basic terms of this category is revealed by a plunge in the decreasing line of indices. This is graphically shown in Diagram 1.

\section{CORE OF THE CATEGORY - BASIC TERMS OF EMOTIONS}

Viha 'anger', armastus 'love', rõóm 'joy' and kurbus 'sadness', turned out to be the basic emotion terms in the Estonian language. The corresponding emotion concepts are the representative members of the category in the consciousness of Estonians. These concepts are also connected with the physical, social and intrapsychic space, 
and therefore they are appropriate objects of the basic level (Rosch 1976). Namely, these emotions have a specific and recognisable external form ${ }^{5}$ - the facial expression that mediates the internal state and functions as a means of communication. As regards the external form, the prototypical emotions can be connected with the physical space, as regards the communicative role, they can be related to the social space. The basic emotions have inherent prototypical behavioural expressions that the informants also knew well. Sadness is prototypically related with crying, joy with laughter, anger with rage, love with hugging and kissing.

A characteristic feature of a prototypical basic emotion concept is for Estonians also the existence of the opposite emotion concept: the positive emotion term is opposed by the negative one and vice versa. The basic emotion terms form pairs: anger (negative) - love (positive) and joy (positive) - sadness (negative). Maybe love, the emotion without facial expression, belongs among the basic emotions just because anger needs an opposite. This typical feature of the category of emotion - bipolarity, division between the good and the bad - can also be detected with emotion terms that position further from the basic level. This is not typical to Estonians only, but it is a semantic universal for the conceptualisation of emotions (Wierzbicka 1999).

This semantic universal becomes most intensive as it moves in the concept hierarchy upward from the basic level, towards generalisation, "where the non-specific meaning outweighs the specific meaning"6 (Allik 1997). Even people who had difficulties with naming emotion words or cognizing emotions, agreed at least to the division of emotions into positive and negative ones. Yet, they could not name more than "well, all those good ones" or "well, all those bad ones". In one task of free listing the informants also had a task name neutral emotions. Many declared bluntly that in their opinion there were no such emotions, yet some could be pointed out (e.g. indifference, tiredness, calm). Also qualities and phenomena emerged that cannot be classified as good or bad, e.g. silent, seriousness, reflective, usual, normal, calm. These concepts are evidently related to emotion category through the reference to the lack of emotion in a situation it could be present. 


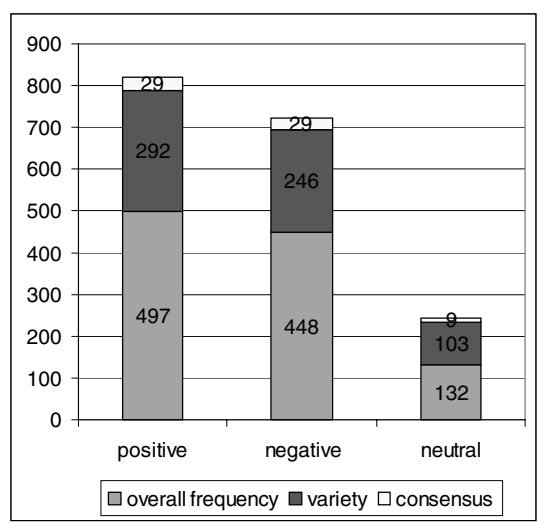

Diagram 2. The number of differentiated emotion terms in the task of free listing subcategories.

It is said to be a general tendency that languages have more words for naming and discerning negative emotions, but words denoting positive emotions are used more frequently (Allik 1997). The abundance of negative emotion words is explained with the struggle for existence, which in the course of time has forced people to develop the terminology for distinguishing danger signals of different kinds. In the tasks of free listings informants were eager to mention positive emotions, the overall frequency and variety of which appeared to be relatively higher. Among the more frequently mentioned words $(3+n$ times $)$ that represent the national consensus of the emotion category, strangely, there was an equal number of both positive and negative ones. The salience proportion of positive, negative and neutral emotion words is illustrated in Diagram 2.

Partially, the significant semantic polarity of emotion vocabulary can also be explained via the principle of the strongest perceptual contrast used in the tasks of free listings - the tendency to distinguish and find names primarily for the phenomena that differ from each other to the greatest extent - this was expressed mainly in naming the emotion words in antonymic pairs (e.g. nutt 'crying' naer 'laughter', rõõm 'joy' - kurbus 'sadness'). Yet, Estonians' treatment of emotions cannot be regarded as totally black and white: the principle of the weakest contrast was also reflected in the experiment - the tendency to name synonymic or semantically close words side by side (e.g. armastus 'love' - hellus 'fondness' - soojus 'warmth'). 


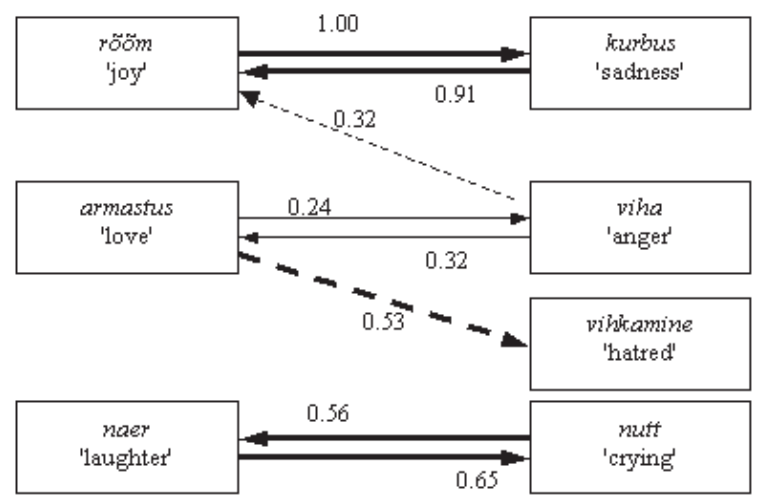

Figure 2. The strongest antonymic relations.

Estonians agreed most frequently on the antonymity of the word pair rõóm - kurbus 'joy - sadness', followed by naer - nutt 'laughter - crying' and viha - armastus 'anger - love'. These three were symmetrical antonymic relations. Additionally, the following asymmetric antonymic relations emerged: armastus - vihkamine 'love hate' and viha - rõom 'anger - joy'. The relative strength of antonymic relations in comparison with the strongest relation (rõom - kurbus 'joy - sadness') is shown on Figure 2. Bold arrows indicate a relatively higher strength of a relation $\left(\mathrm{rS}^{3} 0.50\right)$, while the dashed arrows indicate asymmetrical relations. While all the basic concepts are somehow related, crying and laughter, the behavioural expressions of the basic emotions form a separate autonomous opposition. Yet the respondents were most unanimous in this respect - the only deviation was that 'tears' were twice given as the opposite of 'laughter'.

In other cases the belief in the existence of opposites tended to be greater than agreement in specific antonyms. It seemed that it was the emotion concepts rather than specific emotion words that were opposed in the consciousness of the informants. The concepts could be expressed by different words, for instance viha 'anger' could be expressed as viha 'anger', vihkamine 'hate', vihatunne 'feeling of anger', vihastamine 'getting angry', etc. One factor that could explain the incongruity of opposite words is the individual's personal relationship with this emotion or the lack of such relationship. For example, while for one person the lack of love means hatred, for 
another it may mean loneliness, indifference or jealousy. In this case the opposite word to the basic emotion term was found among non-basic emotion concepts that most precisely described one's personal experience.

\section{NON-BASIC EMOTION CONCEPTS}

On the secondary level there are the more specific developments of the prototypical basic concepts, for example concepts that distinguish feelings on the basis of duration or intenseness: love $>$ passion, sadness $>$ distress, hate $>$ fit of rage, joy $>$ ecstasy. While the basic terms are monolexical native words that can be used in any context, the non-basic words are characterised by the specific context of use: for example foreign words are primarily used in the professional terminology of psychologists (e.g. melanhoolia 'melancholy', depressioon 'depression', agressiivsus 'aggressiveness', eufooria 'euphory'). Several word forms emerge beside the noun, mostly adjectives (e.g. kuri 'evil', tige 'ill-natured', onnelik 'happy') and verbs (e.g. pahandama 'to scold'). On this level there are also compound nouns (meele+heide 'despair', literally: 'thrown out of mind', paha+meel 'displeasure', literally: 'bad mind', hinge+valu 'grief', literally: 'pain of soul'). In addition to primary emotion terms there are also secondary references - the emotion is referred to by means of the quality (e.g. ägedus 'vehemence', tigedus 'spitefulness', karmus 'severity', onnetus 'unhappiness'), or the name of the process or status (e.g. ärritus 'irritation', ahastus 'distress', joovastus 'intense joy').

The specific concepts of non-basic emotions include both the valence (+/-) of the emotions and the qualitative features that connect them with basic emotions. For example, hate is related to displeasure, evil, scold, spiteful, vehemence, strictness, irritation, irritatedness, resentment, hostility and aggressiveness; sadness to distress, despair, worry, sorrow, unhappiness, anxiety, depression, self-pity, bad mood, grief and melancholy; joy to good mood, intense joy, enjoyment, euphory and ecstasy; love to falling in love, fondness, passion, warmth and tenderness.

The antonymic relations between the non-basic emotion words showed either great diffuseness or were rarely existent at all. At 
the same time the belief in the existence of opposites was great, as was the eagerness of people to invent them. The informants had different strategies for finding the specific opposite word, one of them was opposing the emotion to the lack of it, using purely formal means like negation (e.g. onnn - onnne-tus ${ }^{7}$ happiness - unhappiness' or 'fortune - misfortune', but also valu - *mittevalu 'pain *non-pain', hirm - *mittehirm 'fear - *non-fear') or semantically (e.g. rage - indifference, envy - indifference, love - indifference). Another strategy was naming the extreme opposite emotion (or quality or state) (e.g. pain - pleasure, fear - courage, rage - intoxication with joy, envy - altruism).

More than the specific words the emotion concepts or personal images and memories of experienced emotions seemed to be in the consciousness of the informants.

\section{PERIPHERY}

Yet further from the centre of this category are emotion concepts that are less similar to prototypical emotions (hate, love, joy and sadness) and that belong more or less to the three above-mentioned main domains - physical, social or intrapsychic space. In the meaning of these words their negative or positive valence to some degree outweighs their specific emotional meaning. For instance it is easier to decide that envy is bad and friendship is good than whether they are emotions at all. Maybe envy is a personality trait instead and friendship - a social phenomenon like a human relation?

The importance of the physical space for the conceptualisation of emotions is confirmed by the knowledge and experience of the size of the bodies, their movement, temperature, comprehension of their causality etc that are gained by means of sensory abilities. The senses of seeing and hearing mediate the expressive actions of emotions (e.g. crying, shouting, laughter, cheers), the sense of contact mediates subjective experience (e.g. pain, suffering, lightness), sensitivity to temperature is an appropriate source for metaphorical evaluations of emotions (e.g. cold, warmth in the case of describing an attitude to another person). 
The social space involves interpersonal relationships. This field comprises knowledge and experience gained from communicating with other people, for example the acceptance of social behavioural norms - knowledge about accepted and disapproved behaviour and qualities. Lots of words emerged in this semantic group, which shows that the domain of social space is very important for Estonians and it is therefore well subdivided. Division into the good and the bad covers both the subjects of the interpersonal space (the people) and the relationships between them. On this basis the following groups of social emotions are specified.

The good feelings of good people towards good people are friendship, liking, partiality, longing, helping, sympathising, sense of duty, considerateness, trust, respect, pride. The bad feelings of good people to good people are envy and jealousy. The good feelings of good people towards bad people are understanding, indulgence, sympathy, empathy, forgiveness, tolerance. The bad feelings of good people towards bad people are offence, indignation, disappointment, disdain. Bad people seem to be devoid of good feelings. The bad feelings of bad people to good people are inconsideration, intolerance and their share among good people shall be loneliness, shame and guilt. Similarly to the good qualities that favour communication - friendliness, kindness, sincerity, cordiality, benevolence, diligence, openness, gentleness, tolerance, sympathy, attentiveness and helpfulness - the negative human qualities that hinder communication - stupidity, vanity, narrow-mindedness, maliciousness, greediness, impudence - are related with the interpersonal space and emotions.

The internal space is formed of awareness and experience of intrapsychic processes. To this field belong the subjective evaluations of liking and attraction, the subjectively experienced levels of excitement and intensity of will. But also awareness of knowledge, memory and perceptual processes. The words meeldiv 'pleasant', mugav 'comfortable', mõnu 'enjoyment', nauding 'pleasure', rahulolu 'contentment', rahul 'content', heaolu 'well-being', positiivne 'positive' refer to liking evaluations; ebameeldiv 'unpleasant', vastikus 'disgust', rahulolematus 'discontent', kole 'ugly', refer to unpleasantness. The words huvi 'interest', põnevus 'excitement', vaimustus 'enrapturement', entusiasm 'enthusiasm' refer to the evaluation of attraction. 
Igavus 'dullness', tuimus 'apathy', tundetus 'insensitivity', tüdimus 'boredom', mõttetus 'senselessness', ükskõiksus 'indifference', refer to the lack of attraction. Ergas 'alert' indicated the subjectively experienced high energy level, jõuetus 'powerlessness', vaev 'trouble', väsimus 'tiredness', puhkamine 'resting', lõdvestumine 'relaxation' expressed low energy level. Vabadus 'freedom', kindlus 'security', enesekindlus 'confidence', saavutus 'achievement', soov 'wish', lootus 'hope', ootus 'expectation' pointed to will and ebakindlus 'insecurity', lootusetus 'hopelessness', suutmatus 'inability' to the weakness of will. The level of decreasing positive excitement is characterised by the sequence of words like elevil 'excited', erutus 'excitement', julgus 'courage', hingerahu 'peace of mind', rahulik 'composed' and the increasing level of negative excitement by the sequence of words like närviline 'nervous', rahutus 'restlessness', ärevus 'anxiety', ootusärevus 'trepidation', mure 'worry', kartus 'apprehension' and hirm 'fear'. Among the states of mind loomingulisus 'creativity', tasakaalukus 'balance,, usk 'belief', imetlema 'admire' and üllatus 'surprise' are the positive ones and segadus 'confusion', arusaamatus 'misunderstanding', teadmatus 'ignorance', kahetsus 'regret', kõhklus 'hesitation', stress 'stress', kahtlus 'suspicion, unustamine 'forgetfulness' and hämming 'bewilderment' are negative rather than positive.

\section{OUTSIDERS}

There are also terms related to the folk category of emotion, which primarily belong to the three above-mentioned large domains - the physical, social or internal space - and are connected with emotion category through presupposed causality or associative links. To a considerable degree, these words are related to the folk category of emotion because of their division into positive and negative phenomena, which generate positive or negative emotions or help to manage the negative ones. Apparently such things like the sun, flowers, children and family, as these emerged repeatedly, are associated with the collective emotion model of the nation. Generally the individual variation among the associative and causal relations is high - about a third of the mentioned phrases emerged just once. 


\section{BEYOND PERIPHERY}

The fact which feelings and emotions were avoided is as telling as the fact which of them were named. According to a mere intuitive feeling it could already be said that by far not all the emotion terms in Estonian were mentioned in the study. For example, sexualityrelated items seemed to be a taboo. Out of interest I compared the vocabulary that emerged in my empirical study with 210 words from the PONESK-X list ${ }^{8}$, which has earlier been used to study the emotion vocabulary of Estonians (Veski 1996, Allik and Realo 1997). The comparison of the material collected in the empirical study with the exhaustive emotion scale which has been prepared by experts highlighted the fields that are scarcely represented or not represented at all in the collective consciousness of Estonians, or that have voluntarily been excluded from emotion category.

The part in which the laymans' and experts' scale overlap is only about a fourth. The differences have clear tendencies: the laymans' scale consistently lacked word groups referring to certain feelings. Words indicating to positive satiety of energy or will present in experts's list were rarely or never mentioned by the subjects (the word form in Estonian follows the PONESK-X survey list): agarana 'eager', elavana 'lively', lõõgastunud 'relaxed', toimekana 'busy', tragi 'brisk', tublina 'efficient', uljana 'daring', vahvalt 'bold', virge 'alert', järjekindel 'persistent', sundimatult 'casually', südina 'spirited', aktiivsena 'active', elurõõmsana 'cheerfully', energilisena 'energetic', entusiastlik 'enthusiastic', jõulisena 'vigorous', reipana 'sprightly', otsustav 'decisive', tahtekindlana 'determined', tugevana 'strong', visadust 'tenacity'. Rarely such words were mentioned that denote the expression of anger in aggressive behaviour (e.g. tülinoriv 'cantankerous', julmana 'cruel', riiakana 'quarrelsome'). The concept of fear was not extensively subdivided either: the words that mean the different grades of fear were not numerous, e.g. kabuhirmul 'panicky', pelglikult 'timid', kõhedalt 'uneasy, were missing. Words that refer to the feeling of inferiority were abundantly represented in the expert scale, but nearly inexistent in the laymans' scale. Missing were terms of social inferiority terms (e.g. armetuna 'miserable', haavunud 'hurt', haletsusväärsena 'pitiful', häbistatuna 'ashamed', hädisena 'feeble', hüljatuna 'rejected', mahajäetuna 'abandoned', alandatuna 'humiliated', allasurutuna 'suppressed', petetuna 
'cheated'), situational inferiority (e.g. hädas 'in trouble', kimbatuses 'embarrassed', kitsikuses 'stranded', kohmetunud 'constrained', nõmedalt 'vacuous', süümepiina 'pang of guilt', piinlik 'embarrassing', häbelikkus 'bashfulness', ujedust 'shyness', tobedalt 'silly', kohkunud 'taken aback', naeruväärsena 'laughable') as well as mental inferiority (e.g. nüristunud 'numb', peast segasena 'out of one's mind', endast väljas 'upset', hullunud 'maddened', meeltesegaduses 'in mental confusion').

Therefore some blank spots were discovered in Estonians' cognized emotion landscape - feelings that Estonians either do not know, do not remember, do not want to remember or do not want to think and talk about. Or maybe there simply are no appropriate words that would belong to the folk category of emotion even peripherally?

Certain subjects, however, were clearly overrepresented in the laymans' scale. The folk category of emotion seems to be intertwined with popular system of values that also operates with plusminus evaluations. The majority of words that were not included in the experts' list referred to concepts of social space, which presented ideal, recommended qualities, feelings and phenomena (e.g. armastus 'love', rahulolu 'contentment', sõprus 'friendship', sõbralikkus 'friendliness', lahkus 'kindness', lootus 'hope', meeldimine 'liking', vabadus 'freedom', igatsus 'longing', poolehoid 'sympathy', usaldus 'trust', abivalmidus 'helpfulness', sallivus 'indulgence', heaolu 'well-being', mõistmine 'understanding', nali 'joke', töökus 'diligence', tasakaalukus 'balance', avameelsus 'openness', empaatia 'empathy', heatahtlikkus 'benevolence', lahke 'kind', lugupidamine 'respect', aitamine 'helping', andestamine 'forgiveness', hingerahu 'peace of mind', hoolivus 'caring', imetlema 'admire', saavutus 'achievement', siirus 'sincerity', soov 'wish', südamlikkus 'cordiality', tolerantsus 'tolerance', turvalisus 'safety'). As a counterbalance, anti-ideal, socially undesirable feelings, personality traits and phenomena were named (e.g. rahulolematus 'discontentment', agressiivsus 'aggressiveness', depressioon 'depression', teadmatus 'ignorance', kartus 'fear', nördimus 'indignation', hoolimatus 'inconsideration', pahameel 'displeasure', õelus 'malice', ahnus 'greed', arusaamatus 'misunderstanding', karmus 'severity', sallimatus 'intolerance', edevus 'vanity', hingevalu 'grief', kahetsus 'regret', kannatus 'suffering', 


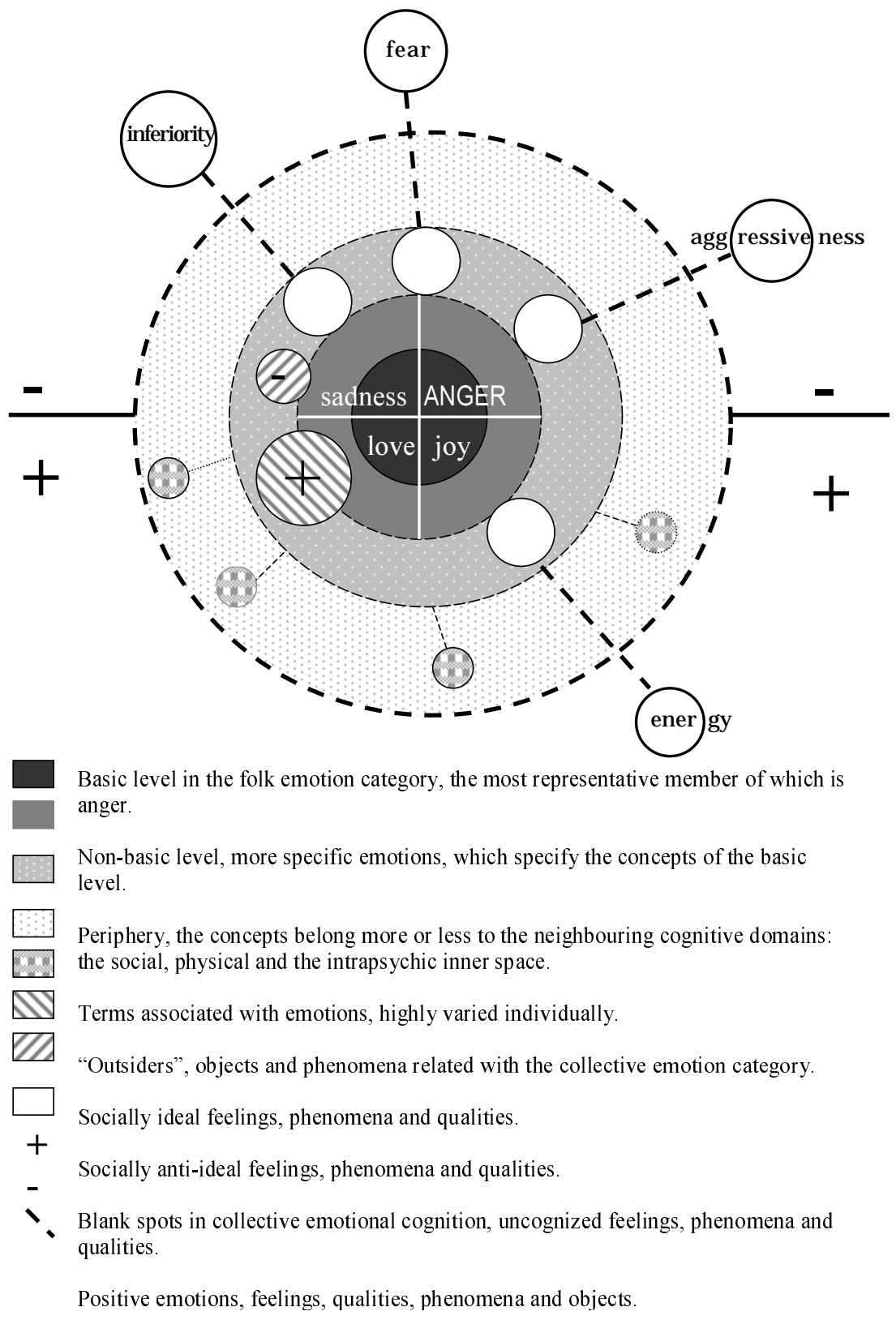

Figure 3. Estonians' folk category of emotions 
melanhoolia 'melancholy', mõttetus 'senselessness', stress 'stress', vimm 'resentment', väiklus 'meanness').

Social norms and magic thinking seem to rule in Estonians' folk category of emotion. Words that refer to social inability (social and situational inferiority) or deviation from the norm (mental inferiority) are rather not said, as if the mere mentioning of these words would bring about these phenomena. The scarcity of words indicating abundance of energy may mean that this quality is not socially valued. The default norm accepted among Estonians does not include enthusiasm, self-confidence and activeness. According to an Estonian saying, excessive eagerness is idiocy.

Figure 3 illustrates Estonians' folk category of emotion in a multilayered form, like it was revealed in the empirical study of emotion vocabulary. The following facts should be noted:

- The basic level is compact and cognitively most salient. It is divded qualitatively between four basic emotion concepts.

- The category is divided into the positive and the negative, the precise quality of the emotion is important for the emotion concepts of the basic and non-basic level.

- Folk emotion category is remarkably rich in social feelings, phenomena and personality traits.

- Certain semantic groups are missing in the collective emotion category.

\section{ANGER AS THE PROTOTYPICAL EMOTION OF ESTONIANS?}

The regularity can be inferred that in Estonian folk psychology when the essence of the emotion is not precisely brought forth, the negative meaning and evaluation is attributed first. This inference is explained by the fact that for Estonians the most prototypical, bestremembered and least marked member of the emotion category appered to be anger. 
Anger enjoys the privilege of representing a whole folk emotion category in Estonians' collective consciousness. On Diagram 1 the word viha 'anger' differs from other basic emotion terms nearly as much as the basic terms from non-basic terms. Therefore, the status of anger is special in Estonians' treatment of emotions. The negative aura that surrounds anger casts shadows on the category of emotion as a whole and this is characteristic not only to Estonians, but also typical to e.g. Anglo-American culture (Stearns 1994).

It may not be surprising, that viha 'anger' appeared to be the most clearly polysemic word - it was also the most frequently named word. According to linguistic economics the frequency of a word also correlates to its formal simplicity and multiplicity of meanings (Zipf 1968). The equally frequent antonyms to the word viha 'anger' were armastus 'love' and rõom 'joy'. Therewith, the opposite relation existed only with the word armastus I would draw the conclusion that in the consciousness of Estonians anger has two interrelated meanings.

The first and primary meaning is the opposite of love and clearly a social feeling related to a human object. In this meaning the synonym of viha 'anger' is vihkamine 'hate'. It seems that viha in this first meaning is understood as a continuous, active process concerning the subject. The other meaning is the opposite of rõom 'joy' and in this meaning the passive state of the subject is stressed. The synonym of viha in this second meaning could be vihastamine 'getting angry' or 'getting frustrated' which can - but does not have to - be related with a human object. Supposedly, in this meaning anger is understood as momentary rather than continuous, similarly to the antonymous joy.

Nowadays the primary meaning of viha is its active and social meaning but not necessarily in the language history. The word viha originally marked a phenomenon of another cognitive area, namely the domain of taste perception as the original meaning of this word was 'bitter'. It can be concluded on this basis that historically the primary meaning was just the one of state or quality - viha was first noticed and named as a bitter feeling - rather than a social attitude. Even today the word viha has preserved this meaning, but it can hardly be associated with emotions in folk consciousness. 


\section{LAYMANS’ VS. EXPERTS’ MODEL OF EMOTIONS}

As the results of the tasks of free listings showed, anger, love, joy and sadness belong to the basic level in Estonians' folk emotion category. In the science of psychology there is debate over which emotions are basic and whether they can be listed at all (Allik 1997). For practical reasons, however, applied psychology considers six basic emotions - anger, joy, sadness, fear, surprise, disgust - they are more or less associated with culturally universal facial expressions (Ekman 1982).

Estonians' opinion of basic emotions coincides with the expert opinion in terms of anger, joy and sadness. The fact that these emotions are important, easily recognised and evidently frequent emotions, is supported by the frequency of naming words that appoint to the prototypical behavioural expressions of these emotions (e.g. crying, laughter, rage). Estonians seem to focus on behavioural expressions rather than facial expressions (smile was mentioned only in one case out of five thousand!). Differently from experts, Estonians also regard love as an emotion.

The words hirm 'fear', vastikus 'disgust' and üllatus 'surprise' do exist in the consciousness of Estonians but they are not as usual and actively used as viha 'anger', armastus 'love', rõom 'joy' and kurbus 'sadness'. Fear, surprise and disgust, classified by psychologists as basic emotions on the basis of facial expressions, do not belong to basic emotions in the opinion of Estonians, maybe because these concepts cannot be used to form antonymous pairs. Evidently also fear, disgust and surprise are feelings that are experienced only in specific situations and in connection with stimuli of specific type -fear in connection with danger, disgust mainly in connection with perceptions of taste or smell, surprise with sudden change of situation. Obviously the interviewing situation did not typically include those stimuli.

Psychologists say that "Estonians cannot think of their emotions in any other way than of positive and negative emotions, whereas these dimensions do not contrast, but are mutually associated in every possible way" (Allik 1997). The tasks of free listings and analysis of results confirmed the first part of this statement - Estonians really tend to think of emotions only as positive or negative ones. In terms 
of the second part of the statement that such negativeness and positiveness are independent, mutually non-opposing dimensions, laymans' opinion diverges from that of experts. The fact that positive and negative emotions are carried in the brain by different substrates does not seem to stop Estonians from regarding emotions as diametrical in their conceptual system of emotions.

The belief emotions can be set in opposition - divided into good (positive) and bad (negative) ones - is firmly fixed in the consciousness of Estonians. People probably do not understand the positiveness or negativeness of emotions in the same way. Depending on circumstances, it may have different content. For instance, emotions were divided into positive and negative ones according to stereotypes, or proceeding from personal views that contradicted the general stereotypical attitudes, e.g. some people classified anger, rage and sadness as positive, one out of a hundred considered joy to be negative.

The division of human experience into positive and negative is a tendency that covers a much more extensive sphere of phenomena than just emotions. Indeed, even in this study not only emotions, but qualities, behaviour, objects, etc. were included in both categories. The question remains whether the plus-minus evaluation primarily represents cultural norms and ethical values (e.g. knowledge about the good and the evil as cultivated by Christianity) or is it a psychological phenomenon - e.g. meta-emotions - i.e. evaluation of emotion as a phenomenon on the basis of personal usefulness-harmfulness (Lazarus 1991).

It is stated that emotion knowledge is divided into two levels (Planalp and Fitness 1999). The first-level preverbal emotion knowledge regulates our behaviour on the basis of an operative plus-minus evaluative mechanism, which is subconscious and has developed in the course of evolution (attack - escape, dangerous - safe, attractive repulsive, pleasant - painful). The socially acquired second-level emotion knowledge is influenced by language and cultural scripts.

Emotion vocabulary and emotion concepts belong among the second-level emotion knowledge, being tools in the process of cognizing emotions. Yet it seems that also first-level emotion knowledge has been encoded in this second level, for example as a preverbal or 
even preconceptual image that corresponds to a subconscious evaluation mechanism, like a kinaesthetic image-schema that is based on bodily experience (approach - retreat). This dualistic first-level emotion knowledge in the form of kinaesthetic image-schema is included in the emotion vocabulary as general and individually for each meaning of an emotion term and it corresponds to the plusminus valence of the emotion.

In general it can be stated that while from the experts' point of view the category of emotions and basic emotions are primarily associated with facial expressions and the process of physiological experience of emotion, for an Estonian layperson emotions are social constructs that are mainly connected with interpersonal relationships and communication. In the experts' opinion emotions belong to individual psychological phenomena, in laymans' opinion - as it emerged from this study of emotion vocabulary - they rather belong to the sphere of social psychology.

I would not dare to compare the opinions as to which one is more correct or which one describes the nature and scale of emotions better. I can only say that in some parts they overlap and in others they do not. For the scientists it is important to match their treatment with the data of modern neurology, experimental provability of results and verifiability of statements. For people it is important to match with each other, keep the good and the evil apart and appeal to themselves and their neighbours.

\section{SUMMARY}

It is not surprising that the category of emotions is located in the subjectively cognized intersection of the physical, social and intrapsychic inner space: emotion - a process subjectively perceived by the individual - has its external physical expressions (expressive behaviour, facial expression, changes in the tone of voice), which in communicative process function as markers of the person's mental or emotional condition. It is characteristic to all the three cognitive domains that border on emotions that feelings, emotions, personality traits, phenomena, activities are divided into the good ones and the bad ones. 
However, the ways in which the category of emotions exists in the consciousness of people are surprisingly manifold. The internal arrangement of this area does not seem to be uniform in the consciousness of all Estonians. Overlaps in the emotion categories of different individuals are on the level of concepts rather than words. Within this empirical study no ready-made order in the concepts or systematic arrangement for preserving (emotion) knowledge could be discerned in the consciousness of language users. The internal systematic order of the cognitive domains does not emerge in the collective consciousness by itself, quite the contrary, it comes into being as a result of research study, analysis and a systematisation effort.

It seems that even though every user of the language knows the map of the collective emotion landscape to a certain degree - in daily life, faced with actual emotion experience, there is no use for $\mathrm{him} /$ her of the hypothetical collective structuredness of this area. In my opinion an average person does not know which emotion knowledge is located in which "locker", he/she mainly uses what is at hand. But the handy ones are the tools that are most frequently needed - primarily the basic-level concepts. An average Estonian knows that more precise and accurate words to denote emotional nuances do exist, but as these concepts are not topical on the daily level, the corresponding words stay "in dust in the locker of consciousness" behind and under everyday things. This empirical study, conducted using the field method, does not by far reveal the entire emotion-related vocabulary in the Estonian language, but it does reveal its more essential part, the part that influences people's everyday life most.

An average Estonian does not usually seem to carry the map of emotion landscape with him/her (and what is the use of a map with blank spots). Yet he/she does have a compass that shows the good and the bad, and awareness of the main cardinal points of emotions - anger, love, joy and sadness.

\section{PRAISE ON LATVIANS}

By ironically calling Estonians "hot-blooded", Latvians do not point to the characteristic feature of Estonians, but to something Estoni- 
ans are typically lacking -facial expressions of emotions. For Estonians emotions are not primarily associated with facial, but with behavioural expressions and social relationships. The emotional life of Estonians belongs not so much to themselves as to the society, to which a higher status has been attributed than to individual values, and the power of making life-changing judgements. Showing emotions makes people vulnerable and can be interpreted as an expression of inferiorty. Estonians hide their emotions probably for safety reasons.

Latvians seem to surmise that Estonians have emotions they do not want to express, moreover, they have emotions they do not want even to accept. Social orientation and protective barriers allow Estonians to handle socially acceptable or ideal emotions only and deplore the anti-ideal ones. Psychoanalysts would say that keeping up such social defense mechanisms absorbs psychic energy, ${ }^{9}$ and presumably they are right - why else the words indicating abundant energy and enthusiasm were missing in Estonians' vocabulary. The Baltic Germans who lived here over centuries have also reproached Estonians for being unenergetic and lazy. ${ }^{10}$

Latvians seem to be a smart nation: they have understood that behind their reticence, Estonians' most prototypical emotion is anger, which burns slowly, smouldering like coals. Estonians tend to direct their rancour inwards, not outwards, treating their neighbours with pretended friendliness or passive aggression.

In case this picture appears too pessimistic, may it be a comfort to us that the major part of irony between nations is caused by envy and those traits of character that one does not easily admit to are most likely projected onto one's neighbours.

\section{Comments}

${ }^{1}$ I would like to express my gratitude to Urmas Sutrop, Kristiina Ross and Haldur Õim for their comments and to all informants who participated in the emotion vocabulary research.

${ }^{2}$ In addition to the emotion terms, the crystallised folk psychology is also linguistically expressed in e.g. phraseological expressions, phrases and grammatical structures, which are used to speak of emotions. 
3 The field method originates from Berlin and Kay's methodology (1969) for the study of colour terms and it includes making experiments of naming the members of a certain category in fieldwork conditions and later an analysis of the psychological aspect of linguistic data.

4 There were a total of seven tasks of listing emotion terms. The more important among them were the first task of free listing, the attempt to name opposites to the terms listed in the first task, the attempt to mention personally experienced emotions and the attempt to elicit positive, negative and neutral emotions terms.

${ }^{5}$ Somewhat surprisingly, love - the emotion without a facial expression belongs to the basic objects in Estonians' treatment of emotions; evidently this feeling is very important in other aspects that compensate for the lack of a specific loving countenance.

${ }^{6}$ Jüri Allik has found out that most of the variation of emotion vocabulary is accounted for by two dimensions: Positive Affect and Negative Affect, which are claimed to be unipolar dimensions, not to be regarded as opposites (Allik 1997, Allik \& Realo 1997).

7 -tu is a suffix reffering to missing quality or thing, -s is a suffix deriving nouns.

${ }^{8}$ PONESK-X - a scale for measuring positive and negative emotions, the results of Veski and Allik are based on it (Veski 1996, Allik 1997). PONESK-X is the Estonian variant of the PANAS-X scale created by Watson and Clark (1994).

${ }^{9}$ Psychoanalysts say that psychic energy is absorbed and engaged by the defense mehcanism of repressing unwanted content from one's consciousness (Freud 1915). What is true on the individual level, is evidently also true on the collective level.

${ }^{10}$ Karl Ernst von Baer writes in his doctoral thesis "On the endemic diseases of Estonians": "I would list the mistakes that still cannot be denied: laziness, dirtiness, excessive humbleness with their superiors and cruelty and rudeness to inferiors" (Baer 1976: 30).

\section{References}

Allik, J. 1997. Eesti keele emotsioone väljendava sõnavara tähendus. Psühholoogia lihtsusest. [The Simplicity of Psychology] Tartu:Tartu Ülikooli kirjastus, pp. 131-150. 
Allik, J. \& Realo, A. 1997. Emotional Experience and its Relation to the Five-Factor Model in Estonian. Journal of Personality. Vol. 65, No. 3, pp. 625-645.

Baer, K. E. v. 1976. Eestlaste endeemilistest haigustest. [On the endemic diseases of Estonians] (1816.) Loomingu Raamatukogu. Tallinn: Perioodika.

Berlin, B. \& Kay, P. 1969. Basic Color Terms: Their Universality and Evolution. Berkeley: University of California Press.

Ekman, P. 1982. Emotions in Human Face. (2nd ed.) New York: Cambridge University Press.

Freud, S. 1915. Repression. Standard Edition 14: 141. London: Hogarth Press. 1957.

Kövecses, Z. 2000. Metaphor and Emotion. Language, Culture and Body in Human Feeling. Cambridge: Cambridge University Press.

Langacker, R. 1987. Foundations of Cognitive Grammar. Vol. I Theorethical Prerequisites. Stanford: Stanford University Press.

Lazarus, R. S. 1991. Emotion and Adaption. Human Emotions: A Reader. J. M. Jenkins, K. Oatley, \& N. L. Stein (eds.). Oxford: Blackwell Publishers, pp. 73-78.

Planalp, S. \& Fitness, J. 1999. Thinking/feeling about social and personal relationships. Journal of Social and Personal Relationships. Vol. 16, No. 6, pp. 731-750.

Rosch, E., Mervis C. B., Gray, W. D., Johnson, D. M. \& Boyes-Braem, P. 1976. Basic objects in natural categories. Cognitive Psychology. 8, pp. 382439.

Stearns, P. N. .1994. American Cool: Constructing a twentieth-century emotional style. New York: New York University Press.

Sutrop, U. 2000. Basic terms and basic vocabulary. Estonian Typological Studies IV. M. Erelt (ed.). Tartu Ülikooli eesti keele ôppetooli toimetised. 14, pp. $118-145$.

Sutrop, U. 2001. List task and a cognitive salience index. Field Methods. 13, pp. 289-302.

Zipf, G., K. 1968. The Psycho-biology of Language: an Introduction to Dynamic Philology. Cambridge, Mass.: M.I.T. Press.

Tulviste, P. 1998. Etnopsühholoogiast ja meist. Rektoriraamat. [On etnopsychology and us. Rector's book.] Tartu: Tartu Ülikooli kirjastus, pp. 53-57.

Vainik, E. 2001. Eestlaste emotsioonisõnavara. [Emotion vocabulary of Estonians] MA thesis (manuscript) in the University of Tartu. http:// www.eki.ee/teemad/emotsioon/

Vainik, E. 2002. Emotions, emotion terms and emotion concepts in an Estonian folk model. Trames No. 4, pp. 322-341.

Veski, E. 1996. Emotsionaalseid seisundeid kirjeldav sõnavara eesti keeles ja selle seos isiksuse omadustega. [Estonian vocabulary describing emotional states and its relation to personal qualities] Diploma thesis (manuscript) in the University of Tartu. 
Viberg, A. 1994. Vocabularies. Biligualism in Deaf Education. International Studies on Sign Language and Communication of the Deaf. 27, pp. 169-199.

Watson, D. \& Clark, L. A. 1994. The PANAS-X Manual for the Positive and Negative Affect Schedule - Expanded Form. Iowa: The University of Iowa.

Whorf, B. L. 1956. Language, Thought, and Reality: Selected Writings of Benjamin Lee Whorf. J. B. Carroll (ed.). New York: Wiley.

Wierzbicka, A. 1999. Emotions across Languages and Cultures: Diversity and Univerals. Cambridge: Cambridge University Press. 